\title{
Recurrent Childhood Anaplastic Oligodendroglioma
}

National Cancer Institute

\section{Source}

National Cancer Institute. Recurrent Childhood Anaplastic Oligodendroglioma. NCI

Thesaurus. Code C115359.

The reemergence of anaplastic olig odendrog lioma in childhood after a period of remission. 